\title{
Epidemiology and surveillance of human animal-bite injuries and rabies post- exposure prophylaxis, in selected counties in Kenya, 2011-2016
}

\author{
Jeremiah Ngurimu Ngugi ${ }^{1,2^{*}}$ (D, Alfred Kilango Maza ${ }^{3}$, Owiti Jack Omolo ${ }^{1,4}$ and Mark Obonyo $o^{1,5}$
}

\begin{abstract}
Background: Human animal-bite injuries are a serious public health problem due to associated risk for rabies virus exposure. Animal-bite injuries especially dog bites are useful indicators for assessing the risk of rabies virus transmission and need for rabies post exposure prophylaxis (PEP). Understanding the epidemiology and surveillance of animal bites and rabies post-exposure prophylaxis is critical in implementing Kenya's national rabies elimination strategy. We aimed to describe the incidence of human animal-bite injuries, patient/biting animal characteristics, uptake of rabies PEP and factors associated with animal bite incidents.
\end{abstract}

Methods: We reviewed animal bite records from outpatient and anti-rabies vaccine (ARV) registers of 17 health facilities from five counties. An animal bite was defined as an entry of an animal bite of the class mammal including humans in registers in a person of any age from January 2011 to December 2016. We collected demographic and information on PEP uptake. We calculated descriptive statistics, odds ratios (OR) and 95\% confidence interval (Cl) to examine factors associated with being an animal bite case-patient. We also calculated incidence of animal bites using health facility catchment population for year 2016 as the denominator.

Results: We analyzed 7307 records. The median age was 22 years (IQR = 31 years); there were $4019(55 \%)$ male and age < 15 years were 2607 (37\%). Dogs accounted for 6720 (93\%) of bites of which 78\% were owned free-roaming dogs. Of the 5674 (88\%) cases that received rabies PEP, 2247 (40\%) got at least three-doses. The median time from bite to seeking medical care was 2 days $(\mathrm{IQR}=4$ days). Being bitten on the head/face $(\mathrm{OR}=5.8 ; \mathrm{Cl}$ : 3.3-10.2); being bitten by owned free-roaming dog $(\mathrm{OR}=1.7 ; \mathrm{Cl}: 1.5-1.9)$ and being male $(\mathrm{OR}=1.4 ; \mathrm{Cl}: 1.3-1.5)$ were significantly associated with being an animal-bite case-patient. Being male, being bitten on head/face and being bitten by owned freeroaming dog remained independently associated with being an animal bite case-patient at multivariable logistic regression. Bite-incidence was 289 bites /100,000 persons among all counties.

Conclusion: Preventing dog bites would most effectively reduce bite injuries by improving public health education among children below 15 years, encouraging early PEP initiation and completion, development and implementation of responsible dog ownership and animal behaviour educational programmes as well as improving human and veterinary health linkages.

Keywords: Rabies, Epidemiology, Post-exposure prophylaxis, Surveillance

\footnotetext{
* Correspondence: jemiahngugi@gmail.com

${ }^{1}$ Kenya Field epidemiology and Laboratory Training Program, Nairobi, Kenya

2Department of Veterinary Services, County Government of Taita Taveta,

Taveta, Kenya

Full list of author information is available at the end of the article
}

(c) The Author(s). 2018 Open Access This article is distributed under the terms of the Creative Commons Attribution 4.0 International License (http://creativecommons.org/licenses/by/4.0/), which permits unrestricted use, distribution, and reproduction in any medium, provided you give appropriate credit to the original author(s) and the source, provide a link to the Creative Commons license, and indicate if changes were made. The Creative Commons Public Domain Dedication waiver (http://creativecommons.org/publicdomain/zero/1.0/) applies to the data made available in this article, unless otherwise stated. 


\section{Background}

Human animal-bite injuries are a serious public health problem owing to the associated risk of rabies virus exposure especially in rabies endemic countries [1-4]. Approximately 85 to $90 \%$ of human animal-bite injuries are caused by dogs, 5 to $10 \%$ by cats and 2 to $3 \%$ by humans and rodents [2]. In low income countries, several studies have demonstrated that dogs account for 76 to $94 \%$ of animal-bite injuries resulting into high prevalence of rabies and higher fatality rates due to poor access to anti-rabies post exposure treatment [5-7]. In Kenya, 146,362 (incidence 336 bites/100,000 persons) animal-bite injuries cases and 858 confirmed human rabies cases from owned free-roaming dogs have been documented between 2002 and $2012[8,9]$.

Rabies is the most significant public health concern following animal-bites' injuries. Other public health concerns following animal-bites include the risk of sepsis of bite wounds, psychological trauma and high cost of seeking PEP for the bite victims [10-12]. Human mortality from canine rabies is estimated at 60,000 annually worldwide, with about $56 \%$ of the cases occurring in Asia and 43.6\% in Africa, mostly in rural areas [8, 13, 14]. In Kenya, rabies is ranked among the top five priority zoonotic diseases and an estimated 1000 to 2000 cases of human rabies occur annually [8]. The human rabies burden in Kenya is thought to be underestimated due to factors limiting the utilization of rabies PEP including poor diagnostic capacity, inaccessibility of anti-rabies vaccine and poor knowledge and practices in management of animal-bite injuries by affected persons $[1,8,13]$. Globally, more than 15 million people receive a post-bite vaccination costing about US\$ 1.7 billion annually [3, 14]. In Africa, approximately 200,000 persons obtains anti-rabies PEP annually following an incidence of animal bite to prevent them from developing rabies [7]. Studies have estimated the average cost of rabies post-exposure prophylaxis (PEP) at US\$ 40 in Africa, and US\$ 49 in Asia resulting into catastrophic financial burden on affected families whose average daily income is estimated at around US\$ 1-2 per person [13-15]. A study in Tanzania found the cost of PEP per animal bite victim to be over US\$ 70 [6], while another study in Kenya found the cost of a single dose of PEP to range between US\$ 8 to US\$ 120 [1]. Kenya's Zoonotic Disease Unit (ZDU) estimated the direct medical cost associated with a complete regime of PEP to be about US\$ 85 per person [8].

Kenya is implementing a national human rabies elimination strategy with a target of achieving zero human deaths from dog mediated rabies by 2030 . Using three pronged approach, the strategy aims to reduce the disease risk through sustained mass dog vaccination, dog population management, pre and post-exposure prophylaxis in humans and public education among animal/ human health workers and the community. With an estimated 5 million dogs in Kenya, $80 \%$ of which have known owners, mass vaccination of owned dogs would cover a substantial population of dogs and can successfully eliminate canine mediated rabies [8]. Animal-bite injuries have been used as a proxy to assess the risk of transmission of rabies virus from animals to humans and determine need for PEP [16]. Surveillance data of animal-bite injuries can also be used as a proxy to estimate an area or region specific rabies burden, thus prioritizing improved rabies surveillance and control [16]. Further, this data can help in understanding patient as well as biting animal characteristics and spatial-temporal distribution of animal-bite injuries $[13,16]$. These are useful indictors in monitoring the success in implementation of the rabies elimination strategy. We therefore aimed to characterize animal bite cases, biting animals' characteristics, and PEP treatment and evaluate the exposure factors associated with the animal-bite injuries.

\section{Methods \\ Study site}

The study was conducted in five counties namely, Machakos and Kitui counties in lower eastern region; Kisumu County in Lake Victoria basin; Nandi County in Central rift valley and Kilifi County in the coastal region. We selected a total of 17 government health facilities offering PEP in the five counties comprising of County referral hospitals, Sub-county hospitals, health centres and peripheral health facilities located in both urban and rural settings (Fig. 1).

\section{Retrospective review of registers}

We reviewed out-patient and anti-rabies vaccine registers in the selected health facilities from January 2011 to December 2016. An animal bite was defined as any entry of an animal bite of the class mammal including humans in the registers for a person of any age during the review period. We defined owned dog as dogs that are always confined or partly confined and spend part of their time at home and part of their time roaming unsupervised outside of the owner's property and the bite injury victim reported they knew the owner. Unowned dogs were free roaming dogs without a known owner. We used a standardized data abstraction tool to collect the following information: date of bite, date seen at health facility, age, sex, residence, species of biting animal, type of biting animal (for only cats and dogs, classified as whether owned or unowned), site of bite, whether PEP was given and number of PEP doses administered Additional file 1. Kenya uses the WHO recommended five intramuscular doses of rabies PEP on days $0,3,7,14$ and 28 and RIG infiltration for category III bites [1]. However RIG is rarely offered to animal bites victims due to the high cost. 


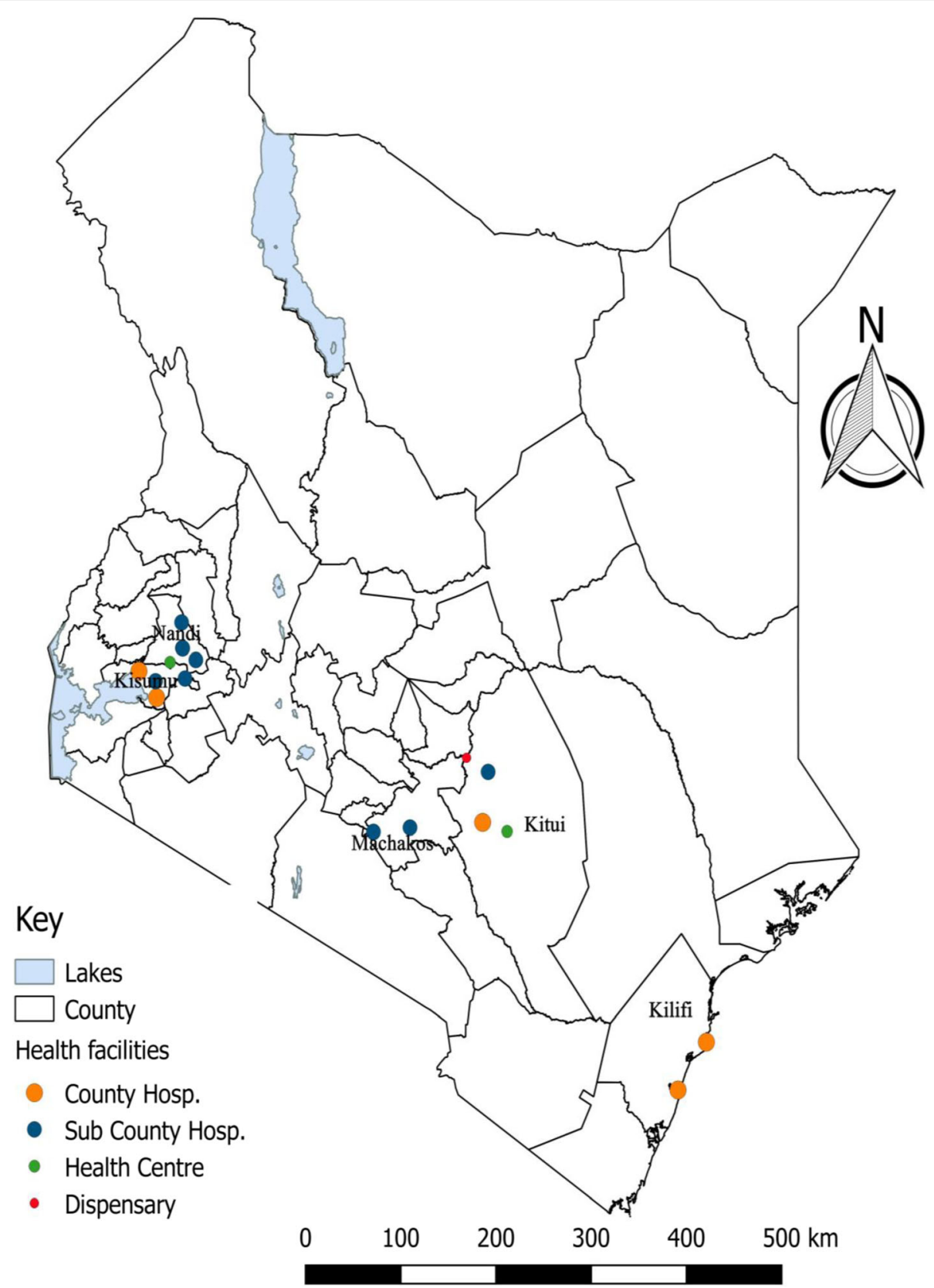

Fig. 1 Study area showing distribution of the study sites - Kenyan Map. Counties Sampled (Map developed by Author using QGIS Version 2.18.10) with geographical data was obtained from https://africaopendata.org/dataset/kenya-counties-shapefile and data on geo - coordinates and category of health facilities was obtained from Kenya Master Health facility list http://kmhfl.health.go.ke/

\section{Data management}

We managed data using Microsoft Excel 2016 (Microsoft, Seattle, WA, USA), and analyzed using Epi Info version 7 (CDC, Atlanta, GA, USA). We calculated proportions for categorical variables and means and medians for continuous variables. We performed bivariate and multivariable unconditional logistic regression analysis and calculated odds ratios (OR), adjusted odds ratio (AOR) and 95\% confidence interval $(\mathrm{CI})$ using age-group $<15$ years and $15+$ years as an dependent variable and other variables such as sex of bite victim, species of biting animal, type of biting animal, site of bite, whether PEP was given or not and number of doses of PEP given as independent variables to determine factors associated with being a bite patient. We also calculated incidence of animal bites per 100,000 persons using the health facility catchment population for the year 2016 as the denominator as well as rate ratio calculated as conditional maximum likelihood estimate (CMLE) 
with 95\% CI for sex, age-group (stratified as $<15$ and 15+ years) and Counties and we considered $p$-value $\leq 0.05$ to be statistically significant.

\section{Results}

\section{Demographic characteristics and site of bite}

Among 7307 records analyzed, 7201 (98.6\%) had age recorded. The median age was 22 years $(\mathrm{Q} 1=11, \mathrm{Q} 3=$ 42 years) and age group 5-14 years old were 2138 (30\%) and $469(7 \%)$ were children under five years. Of 7305 (99.9\%) records where sex was captured, 4019 (55\%) were male. A total of 3345 (66\%) lower extremities (leg/ thigh), $987(20 \%)$ on arms and $210(4 \%)$ in the head/face (Table 1).

Overall, the population adjusted human animal-bite injuries incidence was 289 per 100,000 persons with the highest incidence reported in Kilifi at 302 per 100,000 and lowest in Machakos at 121 per 100,000 persons. The age-group < 15 years had a higher incidence in Kitui, Machakos and Nandi counties while males had a higher incidence across all the counties. There was a statistical significant difference in bite incidence for sex, age-group and Counties $(p$-value $\leq 0.05)$ (Table 2).

\section{Delay in seeking treatment and PEP administration}

The median number of days between contact with biting animal and presenting at a health facility was 2 days (Q1 $=1, \mathrm{Q} 3=6$ days). A total of 1989 (57\%) of the animal-bite victims accessed a health facility within the first two days after the bite (Fig. 2). Among the counties, 295 (100\%) bite cases in Machakos, 1739 (99\%) in Nandi and $844(67 \%)$ in Kitui were started on rabies PEP. At-least 2247 (40\%) of the cases received three doses of PEP with 768 (75\%) in Kilifi, 198 (67\%) in Machakos, $410(49 \%)$ in Kitui, 483 (28\%) in Nandi, and $388(22 \%)$ in Kisumu (Table 1).

\section{Biting animal characteristics}

Of the 7270 (99.5\%) cases whose records on biting animal were recorded, 5208 (72\%) bites were inflicted by owned-dogs, with 270 (92\%) in Machakos, 1575 (82\%) in Kilifi, 1315 (76\%) in Nandi, 990 (78\%) in Kitui, and 1058 (51\%) in Kisumu. Un-owned dogs were responsible for $1512(21 \%)$ of the bites distributed with $899(43 \%)$ recorded in Kisumu, 324 (17\%) in Kilifi, 170 (13\%) in Kitui $16(5 \%)$ in Machakos and 103 (6\%) Nandi (Table 1).

\section{Exposure factors}

Children below 15 years had increased chances $(\mathrm{OR}=1.7$, $95 \%$ CI: $1.5,1.9)$ of being bitten by owned-dogs compared to those aged above 15 years. However unowned dogs had lower chances $(\mathrm{OR}=0.6,95 \% \mathrm{CI} 0.5,0.7)$ of causing bite injuries in children below 15 year olds compared to children above 15 years old. Male below 15 years had increased chances of suffering animal-bite injuries compared to female of the same age category $(\mathrm{OR}=1.4,95 \%$ CI 1.3, 1.5) and children below the age of 15 years had increased chances $(\mathrm{OR}=5.8$ (95\% CI 3.3, 10.2) of having bites inflicted on the head and face compared to those aged above 15 years (Table 3). On multivariable unconditional logistic regression analysis: being male $(\mathrm{aOR} 1.5$ (95\% CI 1.3, 1.7), having bite injuries on the head/face (aOR $1.8(95 \%$ CI 1.3, 2.6) and being bitten by owned dog (aOR 1.2 (95\% CI 1.1, 1.3) remained significantly associated with the being animal-bite.

\section{Discussion}

This study demonstrates that animal-bite injuries remain an important cause of morbidity and reason for visiting health facilities in Kenya. This is important since bite injuries is the main mode of transmission of human rabies $[3,6-8,10]$. This study also identified high risk groups for animal-bite, culpable animals that are most likely to cause bites and exposure factors associated with animal-bite. This are useful information that may inform policy makers and implementers of the national human rabies elimination strategy in Kenya of ways they can design possible interventions with most impact to reduce human rabies.

Owned dogs were implicated in most animal-bite injuries. This is consistent with other studies that have implicated owned dogs in most of bite injury incidents $[1,16]$. In Kenya and many other rabies-endemic countries dog owners allow their dogs to roam freely $[17,18]$, which increases an animals' risk for rabies virus exposure and transmission to other animals and also humans. In Kenya, a study conducted in Machakos County, reported that only $29 \%$ of the owned dogs were vaccinated against rabies. Similar reports by ZDU-Kenya indicated that only $23 \%$ of owned dogs were routinely vaccinated in Makueni county $[17,18]$ while another study estimated that dog vaccination coverage in Kenya was $0.5 \%$ [3]. In tandem with the increased use of dogs as companion and guard animals in Kenya, the number of dog bites is likely to increase and as a result there will likely be an increase in rabies transmission especially in rural areas where dogs are not leashed and move freely thereby increasing the risk of exposure to rabies [16-19].

While the most frequently bitten body part was the limbs, children were predisposed to bites on the head and face due to their stature [20]. Animals bites to the head and face are especially risky due proximity to the central nervous system and clinical progression to rabies is highly likely if the bite occurs from a rabid animal. It is therefore advisable that such children should receive immediate PEP and rabies immunoglobulin (RIG) treatment as soon as possible to prevent any possibilities of getting rabies. However in Kenya and most sub-Saharan Africa where rabies is endemic, this may not be possible 
Table 1 Demographic characteristics, bite location, biting animal and PEP treatment among animal bite victims distributed by County, 2011-2016

\begin{tabular}{|c|c|c|c|c|c|c|}
\hline Variable & $\begin{array}{l}\text { All cases } \\
\mathrm{n}(\%)\end{array}$ & Kilifi $(n=1931) \mathrm{n}(\%)$ & Kisumu $(n=2071) \mathrm{n}(\%)$ & Kitui $(n=1266) \mathrm{n}(\%)$ & Machakos $(n=295) \mathrm{n}(\%)$ & Nandi $(n=1762) \mathrm{n}(\%)$ \\
\hline \multicolumn{7}{|l|}{ Sex } \\
\hline Female & $3286(45)$ & $822(43)$ & $872(42)$ & $604(48)$ & $144(45)$ & $844(48)$ \\
\hline Male & 4019 (55) & $1091(57)$ & $1199(58)$ & $662(52)$ & $151(51)$ & $916(52)$ \\
\hline \multicolumn{7}{|l|}{ Age group } \\
\hline$<5$ & $469(6)$ & $91(5)$ & $50(2)$ & $100(9)$ & $25(9)$ & $203(11)$ \\
\hline $5-14$ & $2138(30)$ & $686(36)$ & $231(11)$ & $520(45)$ & $116(39)$ & $585(33)$ \\
\hline $15-24$ & $1236(17)$ & $344(18)$ & 391 (19) & $165(14)$ & $42(14)$ & $293(17)$ \\
\hline $24-39$ & $1381(19)$ & $354(19)$ & $462(22)$ & $169(15)$ & $52(18)$ & $341(20)$ \\
\hline $40-59$ & $1464(20)$ & $298(16)$ & $735(36)$ & $135(12)$ & $46(16)$ & $248(14)$ \\
\hline $60+$ & $513(7)$ & $140(7)$ & $202(10)$ & $74(6)$ & $14(5)$ & $83(5)$ \\
\hline \multicolumn{7}{|l|}{ Bite location } \\
\hline Leg/Thigh & $3345(66)$ & $681(64)$ & $1343(65)$ & $346(57)$ & $204(69)$ & $771(77)$ \\
\hline Arm & $987(20)$ & $281(26)$ & $288(14)$ & $186(31)$ & $52(18)$ & $180(18)$ \\
\hline Trunk & $299(6)$ & $84(8)$ & $172(8)$ & $26(4)$ & $10(3)$ & $7(0.7)$ \\
\hline Head/Face & $210(4)$ & $24(2)$ & $127(6)$ & $22(4)$ & $11(4)$ & $26(3)$ \\
\hline Buttock/Groin & $197(4)$ & Nil & $141(7)$ & $25(4)$ & $17(6)$ & $14(0.7)$ \\
\hline \multicolumn{7}{|l|}{ PEP administered } \\
\hline Yes & $5674(88)$ & $1022(96)$ & $1774(86)$ & $844(67)$ & $295(100)$ & $1739(99)$ \\
\hline No & 789 (12) & $48(5)$ & $297(14)$ & $422(33)$ & Nil & $22(1)$ \\
\hline \multicolumn{7}{|l|}{ No of PEP doses } \\
\hline 1 & 2008 (35) & $145(14)$ & $571(32)$ & $286(34)$ & $58(20)$ & $948(55)$ \\
\hline 2 & $1411(25)$ & $109(11)$ & $812(46)$ & $146(17)$ & $39(13)$ & $305(18)$ \\
\hline 3 & 1100 (19) & $107(11)$ & $365(21)$ & $115(14)$ & $120(41)$ & $393(23)$ \\
\hline 4 & $377(7)$ & $166(16)$ & $23(1)$ & $133(16)$ & $15(5)$ & $40(2)$ \\
\hline 5 & $770(14)$ & $495(48)$ & Nil & $162(19)$ & $63(21)$ & $50(3)$ \\
\hline \multicolumn{7}{|c|}{ Type of biting animal } \\
\hline Owned dog ${ }^{a}$ & $5208(72)$ & $1575(82)$ & $1058(51)$ & $990(78)$ & $270(92)$ & $1315(76)$ \\
\hline Unowned Dog & $1512(21)$ & $324(17)$ & $899(43)$ & $170(13)$ & $16(5)$ & $103(6)$ \\
\hline Owned Cat & $380(5)$ & $14(0.7)$ & $63(3.0)$ & $24(2)$ & $3(1)$ & $276(16)$ \\
\hline Livestock $^{b}$ & $77(1)$ & Nil & $10(0.4)$ & $56(4)$ & $1(0.3)$ & Nil \\
\hline Human & $47(0.7)$ & Nil & $24(1)$ & $11(0.9)$ & Nil & $12(0.7)$ \\
\hline Unowned Cat & $34(0.5)$ & Nil & $17(0.8)$ & $15(1)$ & $1(0.3)$ & $1(0.1)$ \\
\hline Others $^{c}$ & $12(0.2)$ & $\mathrm{Nil}$ & $\mathrm{Nil}$ & $\mathrm{Nil}$ & $4(0.7)$ & $7(0.4)$ \\
\hline
\end{tabular}

${ }^{a}$ Owned dog refers to dogs that are partly confined and spend part of their time roaming unsupervised outside the owner's property while unowned dogs refers free roaming dogs without a known owner

${ }^{\mathrm{b}}$ Livestock includes donkey and pig.

cothers include monkeys, rats, hyena and other wild animals.

due to several factors including distance from nearest health facility, availability of PEP and RIG in the health facilities and costs associated with obtaining PEP [1].

In this study, children below the age of 15 years comprised more than a third of the cases of animal-bite injuries. The same age group also had increased chances of suffering bite by owned dogs compared to unowned dogs. These findings are similar to previous studies that reported dog bites to be a major public health problem worldwide especially among male children below the age of 15 years $[2,4,9,13]$. This is very critical in rabies elimination strategy using mass dog vaccinations since this age group are the ones who normally bring dogs for vaccinations (authors observation) and they are also critical group for targeting public health education to prevent rabies transmission following an incident of animal-bite including 
Table 2 Population adjusted human animal-bite injuries incidence per 100,000 persons by Sex, Age group and County, $2011-2016$

\begin{tabular}{|c|c|c|c|c|c|c|}
\hline Variable & $\begin{array}{l}\text { Catchment } \\
\text { pop (Yr. 2016) }\end{array}$ & Bite cases & $\begin{array}{l}\text { Average } \\
\text { cases per year }\end{array}$ & $\begin{array}{l}\text { Bite Incidence } \\
/ 100,000 \text { persons }\end{array}$ & CMLE Rate Ratio & $P$-value \\
\hline \multicolumn{7}{|l|}{ Sex } \\
\hline Male & 243,029 & 4019 & 804 & 331 & $1.4(1.2,1.5)$ & $<0.0001$ \\
\hline Female & 272,094 & 3286 & 657 & 242 & Reference & \\
\hline \multicolumn{7}{|l|}{ Age group } \\
\hline$<15$ years & 215,139 & 2607 & 521 & 242 & $0.8(0.7,0.9)$ & $<0.0001$ \\
\hline $15+$ years & 289,984 & 4594 & 919 & 317 & Reference & \\
\hline \multicolumn{7}{|l|}{ Counties } \\
\hline Kilifi & 126,843 & 1913 & 383 & 302 & $0.8(0.7,1.0)$ & 0.0157 \\
\hline Kitui & 93,485 & 1266 & 253 & 271 & $0.8(0.6,0.9)$ & 0.0002 \\
\hline Machakos & 48,684 & 295 & 59 & 121 & $0.3(0.3,0.5)$ & $<0.001$ \\
\hline Nandi & 120,612 & 1762 & 353 & 292 & $0.8(0.7,0.9)$ & 0.0051 \\
\hline Overall & 505,124 & 7307 & 1461 & 289 & $0.8(0.7,0.9)$ & 0.0002 \\
\hline Kisumu & 115,500 & 2071 & 414 & 359 & Reference & \\
\hline
\end{tabular}

wound washing with soap and water, access to PEP and responsible dog ownership.

The PEP completion rates for those who got at least three doses varied across the counties. This is consistent with other studies where persons exposed to rabies did not receive the full course of rabies PEP treatment and often delayed starting the prophylactic treatment $[4,12$, 21]. The low rabies PEP completion rates could be attributed to factors like the high cost of obtaining PEP, long distances to health facilities, multiple referrals, unavailability of rabies PEP in government health facilities among others [1]. WHO guidelines recommends use of rabies PEP and rabies immunoglobulin (RIG) as immediate critical first aid in-order to neutralize the virus before immunity from vaccination develops $[9,15,21]$. Therefore, collaborations between the human and animal health sectors using an integrated one health approach has been demonstrated to significantly improve the number of people starting and completing PEP while reducing the unnecessary use of rabies PEP for non-rabies exposures [22].

\section{Limitations}

The animal bite surveillance in Kenya is passive, as a result the main limitations of this study was incomplete data

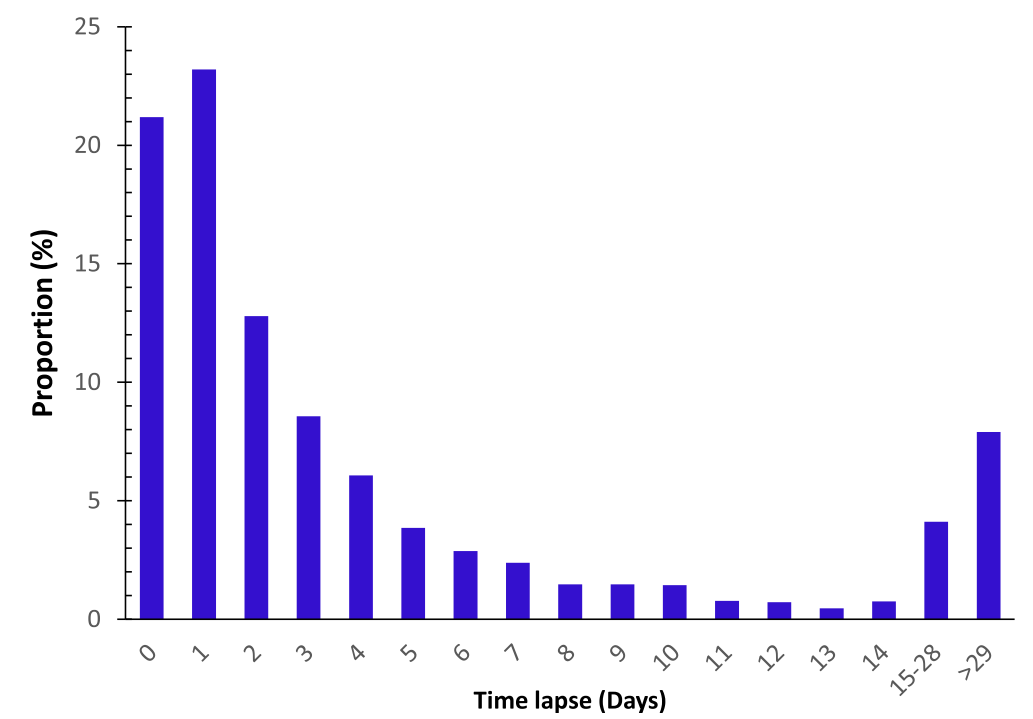

Fig. 2 No of cases (\%) by time in days between contact of bite and visiting a health facility ( $n-3409)$. Proportion of cases (\%) by period (days) that reported to a health facility after an animal bite from 0 to 29 days 
Table 3 Bivariate and multivariable logistic regression analysis for exposure factors associated with animal-bite in selected counties, Kenya, 2011-2016

\begin{tabular}{|c|c|c|c|c|}
\hline Variable & $\begin{array}{l}\text { Young (< } 15 \text { years) } \\
(2351) n(\%)\end{array}$ & $\begin{array}{l}\text { Adult (15+ years) } \\
(n=4382) \mathrm{n}(\%)\end{array}$ & OR $(95 \% \mathrm{Cl})$ & $\begin{array}{l}\text { Adjusted Odds } \\
\text { Ratio (AOR) }\end{array}$ \\
\hline \multicolumn{5}{|l|}{ Biting animal } \\
\hline Owned Dog a & $2011(78)$ & $3094(68)$ & $1.7(1.5,1.9)$ & $1.2(1.1,1.3)$ \\
\hline Unowned Dog & $403(16)$ & 1109 (24) & $0.6(0.5,0.7)$ & NS \\
\hline Cat & $152(6)$ & $262(6)$ & $1(0.8,1.3)$ & NS \\
\hline Human & $3(0.1)$ & $43(0.9)$ & $0.1(0.02,0,38)$ & NS \\
\hline Livestock $^{b}$ & $21(0.8)$ & $55(1)$ & $0.7(0.43,1.11)$ & NS \\
\hline Others $^{c}$ & $2(0.1)$ & $10(0.2)$ & $0.4(0.04,1.66)$ & NS \\
\hline \multicolumn{5}{|l|}{ Sex } \\
\hline Male & $1573(60)$ & $2400(52)$ & $1.4(1.3,1.5)$ & $1.5(1.3,1.7)$ \\
\hline Female & $1034(40)$ & $2193(48)$ & Ref & \\
\hline \multicolumn{5}{|l|}{ Bite Site } \\
\hline Leg/Thigh & $775(60)$ & $1173(74)$ & $0.5(0.5,0.6)$ & NS \\
\hline Arm & $323(25)$ & $344(22)$ & $1.2(1,1.5)$ & NS \\
\hline Trunk & $83(7)$ & 39 (3) & $2.8(1.9,4.1)$ & NS \\
\hline Head/Face & $67(5)$ & $15(1)$ & $5.8(3.3,10.2)$ & $1.8(1.3,2.6)$ \\
\hline Buttock/Groin & $36(3)$ & $17(1)$ & $2.7(1.5,4.8)$ & NS \\
\hline \multicolumn{5}{|l|}{ PEP } \\
\hline Yes & $1942(84)$ & $3629(90)$ & $0.6(0.54,0.72)$ & $0.3(0.2,0.3)$ \\
\hline No & $364(16)$ & $423(10)$ & Ref & \\
\hline \multicolumn{5}{|l|}{ PEP Doses } \\
\hline$\geq 3$ doses & $875(40)$ & $1293(60)$ & $1.5(1.3,1.7)$ & NS \\
\hline$<3$ dose & $1062(31)$ & $2333(69)$ & Ref & \\
\hline \multicolumn{5}{|l|}{ Counties } \\
\hline Kilifi & 777 (30) & $1136(25)$ & $4.4(3.7,5.1)$ & $5.2(4.3,6.3)$ \\
\hline Kitui & $620(24)$ & $549(12)$ & $7.2(6.1,8.5)$ & $6.4(5.3,7.6)$ \\
\hline Machakos & $141(5)$ & $154(3)$ & $5.8(4.5,7.6)$ & $6.1(5.0,8.0)$ \\
\hline Nandi & $788(30)$ & $965(21)$ & $5.2(4.5,6.1)$ & $5.7(4.8,6.8)$ \\
\hline Kisumu & $281(11)$ & $1790(39)$ & Ref & \\
\hline
\end{tabular}

NS Not significant

${ }^{a}$ Owned dog refers to dogs that are partly confined and spend part of their time roaming unsupervised outside the owner's property while unowned dogs refers free roaming dogs without a known owner.

bivestock includes donkey and pig.

cothers include monkeys, rats, hyena and other wild animals.

from the data sources (Outpatient and anti-rabies registers). Further, this study describes patients that seek care in health facilities and therefore miss a critical population that don't seek medical attention. The rabies vaccination status of the animal causing the injury was also unknown, the circumstances of the bite incident and information on whether the biting animals were suspected of being rabid or not was not available. All these limited the scope of analysis for this study.

\section{Conclusions}

Animal-bite injuries from owned dogs remain a major public health problem in Kenya and biggest contributor to rabies exposures especially in male and children below 15 years. To achieve the goal of eliminating dog mediated human rabies by 2030 as enshrined in the Kenya rabies elimination strategy blue print, sustained mass vaccination of owned dogs will be critical. Vaccination of the owned dogs against rabies has been documented to result in significant reduction in the incidence of human rabies and is cost-effective control strategy in the medium to long term $[1,7,8]$. However, other strategies outlined in the document like dog population management, pre and post-exposure prophylaxis in humans and public education among animal/human health workers and the community are also critical in achieving this goal. The success of the 
strategy will require participation and collaboration of every key stakeholder especially Country governments' to allocate resources for mass dog vaccinations and educational sector in development of educational programs for children and dog owners regarding responsible dog ownership and animal behavior to reduce and prevent animal-bite cases. Strengthening Linkage and collaboration between the human and animal health sectors through the one health approach is critical for the success of the strategy.

\section{Additional file}

Additional file 1: Kenya animal bites dataset. (XLSX $1570 \mathrm{~kb}$ )

\section{Abbreviations}

AOR: Adjusted odds ratio; ARV: Anti Rabies Vaccine; Cl: Confidence Interval; IQR: Interquartile Range; OR: Odds Ratio; PEP: Post exposure Prophylaxis; Q1: First Quartile; Q3: Third Quartile; RIG: Rabies Immunoglobulin; US\$: US dollars; WHO: World Health Organisation

\section{Acknowledgements}

We would like to acknowledge the County Directors of Health Machakos, Kitui, Kisumu, Kilifi and Nandi counties for allowing us access to the health records, data abstraction clerks for their dedication and hard work during the course of the study. We also wish to acknowledge JR Ransom for proof reading the manuscript for language and grammar.

\section{Availability of data and materials}

All data generated or analyzed during this study are included in this published article [and its supplementary information files].

\section{Authors' contributions}

JN - developed the initial study concept, data curation and analysis and preparation of the draft manuscript to final submission. AM - supervised the data abstraction clerks during data collection and analysis and drafting of the manuscript. JO - assisted in data curation and analysis and drafting of manuscript. MO - assisted to refine the study concept, data analysis, and critical revision of the manuscript. All the authors have read and approved the final version of the manuscript and have approved its submission for publication. Any individual or institutions named in the acknowledgement section agree to being so named.

\section{Competing interest}

The authors declare that they have no competing interests.

\section{Ethics approval and consent to participate}

The study involved retrospective data review of publicly available surveillance data collected during routine patient management by the Kenyan Ministry of Health $(\mathrm{MoH})$. This information was abstracted from various hard-copy health records/registers (Anti-rabies vaccine and outpatient registers). Verbal permission to access the records was obtained from the health facility administrator in the following health facilities: Kilifi and Malindi county hospitals in Kilifi County; Kisumu county referral hospital, Muhoroni sub-county hospital, Nyakach county hospital and Nyando sub -county hospital in Kisumu County; Kitui county hospital, Mwingi sub-county hospital, Thaana Nzau dispensary and Zombe health center in Kitui County; Kathiani sub-county hospital and Mavoko health center in Machakos County and Aldai sub-county hospital, Chemase health center, Meteitei sub-county hospital, Mosoriot sub-county hospital and Nandi Hills sub county hospital in Nandi County. No ethical approval by an institutional ethics review board was needed and no personal identifying information was collected during data abstraction. The abstracted/collected data was properly stored and secured.
Consent for publication

Not applicable.

\section{Publisher's Note}

Springer Nature remains neutral with regard to jurisdictional claims in published maps and institutional affiliations.

\section{Author details}

${ }^{1}$ Kenya Field epidemiology and Laboratory Training Program, Nairobi, Kenya. ${ }^{2}$ Department of Veterinary Services, County Government of Taita Taveta, Taveta, Kenya. ${ }^{3}$ Regional Veterinary Investigation Laboratory, Mariakani, Kenya. ${ }^{4}$ Department of Veterinary Services, County Government of Kilifi, Kilifi, Kenya. ${ }^{5}$ Ministry of Agriculture, Livestock and Fisheries, Directorate of Veterinary Services, Nairobi, Kenya.

Received: 12 October 2017 Accepted: 25 July 2018

Published online: 09 August 2018

\section{References}

1. Obonyo M, Akoko JM, Orinde AB, Osoro E, Boru WG, Njeru I, Fèvre EM: Suspected rabies in humans and animals, Laikipia County, Kenya. Emerg Infect Dis. 2016;22(3):551-553

2. MacBean CE, Taylor DM, Ashby K. Animal and human bite injuries in Victoria, 1998-2004. Med J Aust. 2007;186(1):38.

3. Hampson K, Coudeville L, Lembo T, Sambo M, Kieffer A, Attlan M, Barrat J, Blanton JD, Briggs DJ, Cleaveland S. Estimating the global burden of endemic canine rabies. PLoS Negl Trop Dis. 2015;9(4):e0003709.

4. Fevre E, Kaboyo R, Persson V, Edelsten M, Coleman P, Cleaveland S. The epidemiology of animal bite injuries in Uganda and projections of the burden of rabies. Tropical Med Int Health. 2005;10(8):790-8.

5. 10 facts on rabies [http://www.who.int/features/factfiles/rabies/en/]. Accessed 13 Mar 2017

6. Sambo MB. Epidemiological dynamics of rabies in Tanzania and its impacts on local communities: University of Glasgow; 2012

7. Knobel DL, Cleaveland S, Coleman PG, Fèvre EM, Meltzer MI, Miranda MEG, Shaw A, Zinsstag J, Meslin F-X. Re-evaluating the burden of rabies in Africa and Asia. Bull World Health Organ. 2005;83(5):360-8.

8. Zoonotic Disease Unit (ZDU) Kenya. In: Ministry of Health and Ministry of Agriculture LaF, editor. Strategic Plan for the Elimination of Human Rabies in Kenya 2014-2030; 2014.

9. Obonyo M, Arvelo W, Kadivane S, Orundu M, Lankau E, Gakuya F, Munyua P, Githinji J, Marano N, Njenga K. Investigation to determine staff exposure and describe animal bite surveillance after detection of a rabid zebra in a safari lodge in Kenya, 2011. Pan Afr Med J. 2014;19:10.

10. Animal bites [http://www.who.int/mediacentre/factsheets/fs373/en/]. Accessed 13 Mar 2017.

11. Steele MT, Ma OJ, Nakase J, Moran GJ, Mower WR, Ong S, Krishnadasan A, Talan DA. Epidemiology of animal exposures presenting to emergency departments. Acad Emerg Med. 2007;14(5):398-403.

12. Joseph J, Sangeetha N, Khan AM, Rajoura O. Determinants of delay in initiating post-exposure prophylaxis for rabies prevention among animal bite cases: hospital based study. Vaccine. 2013;32(1):74-7.

13. World Health Organization (WHO): WHO Expert Consultation on Rabies. In.; 2013.

14. Rabies [http://www.who.int/news-room/fact-sheets/detail/rabies]. Accessed 13 Mar 2017.

15. World Health Organization: WHO guide for Rabies Pre and Post-exposure prophylaxis in Humans. In.; 2010.

16. Mazigo HD, Okumu FO, Kweka EJ, Mnyone LL. Retrospective analysis of suspected rabies cases reported at Bugando referral hospital, Mwanza, Tanzania. J Global Infect Dis. 2010;2(3):216.

17. Kitala P, McDermott J, Kyule M, Gathuma J, Perry B, Wandeler A. Dog ecology and demography information to support the planning of rabies control in Machakos District, Kenya. Acta Trop. 2001;78(3):217-30.

18. Zoonotic Disease Unit (ZDU) Kenya: Dog ecology, incidence of dog bites and canine rabies post-vaccination coverage in Makueni County, Kenya: A cross-sectional survey conducted following world rabies day vaccination campaign, 2014. 2014

19. Schildecker S, Millien M, Blanton J, Boone J, Emery A, Ludder F, Fenelon N, Crowdis $K$, Destine A, Etheart M. Dog ecology and barriers to canine rabies control in the Republic of Haiti, 2014-2015. Transbound Emerg Dis. 2017;64(5):1433-42. 
20. Schalamon J, Ainoedhofer H, Singer G, Petnehazy T, Mayr J, Kiss K, Höllwarth ME. Analysis of dog bites in children who are younger than 17 years. Pediatrics. 2006;117(3):e374-9.

21. Aghahowa S, Ogbevoen R. Incidence of dog bite and anti-rabies vaccine utilization in the, University of Benin Teaching Hospital, Benin City, Nigeria: a 12-year assessment. Vaccine. 2010;28(30):4847-50.

22. Etheart MD, Kligerman M, Augustin PD, Blanton JD, Monroe B, Fleurinord L, Millien M, Crowdis K, Fenelon N, Wallace RM. Effect of counselling on health-care-seeking behaviours and rabies vaccination adherence after dog bites in Haiti, 2014-15: a retrospective follow-up survey. Lancet Glob Health. 2017:5(10):e1017-25.

Ready to submit your research? Choose BMC and benefit from:

- fast, convenient online submission

- thorough peer review by experienced researchers in your field

- rapid publication on acceptance

- support for research data, including large and complex data types

- gold Open Access which fosters wider collaboration and increased citations

- maximum visibility for your research: over $100 \mathrm{M}$ website views per year

At BMC, research is always in progress.

Learn more biomedcentral.com/submissions 